\title{
From Hahnemann to the Physiology of the Complex Systems in Practice
}

\section{Romeu Carillo Jr ${ }^{1 *}$; Maria Filomena Xavier Mendes ${ }^{2 * *}$; Maria Solange Gosik ${ }^{3}$; Domingos J. Vaz do Cabo ${ }^{4}$, Raquel Kalile ${ }^{5}$; Renata Garcia Lino ${ }^{6}$}

\begin{abstract}
1 Head of Homeopathy Clinic - Hospital do Servidor Público Municipal de São Paulo HSPM; Advisor of extension courses of Abrah - São Paulo, Brazil; 2 Master in Neurology UFRJ; Homeopathy phisician in SMS-RJ; Coordinator of Abrah in Rio de Janeiro,Brazi; 3 Pediatric and Homeopathy phisician; National Coordinator of Abrah in Brazil; 4 Master in Public Health - FIOCRUZ; Pediatric, Homeopathy and family and community medicine phisician, Brazil; 5 Homeopathy phisician; General supervisor of homeopathy ambulatory of Abrah in Rio de Janeiro,Brazil; 6 Pediatric and Homeopathy phisician; Supervisor of homeopathy ambulatory of Abrah in Rio de Janeiro, Brazil. Email: *romeucarillo@gmail.com; **filoabrah@yahoo.com.br
\end{abstract}

\begin{abstract}
Background: Amyotrophic Lateral Sclerosis is a progressive and fatal neurodegenerative disease that affects motor neurons and has two forms, one familial and the other sporadic. Wilson's disease is a genetic disorder, autosomal recessive, which causes changes in copper metabolism.

Methodology: In this paper, the author presents two clinical cases of patients with amyotrophic lateral sclerosis (ALS) and Wilson's disease (WD), showing the evolution of each one from the beginning of the homeopathic treatment, whose prescription was based on the theory of Complex Systems of Carillo.

Results and Discussion: Understanding the pathophysiology of each chronic disease, and recognizing the syndromic nature of the absolute majority of natural chronic diseases, allows us to use the most indicated drugs for everyease and shows the best way to prescribe these medications. Treating chronic diseases based on clear and well-defined principles. Based in this principle, the concepts of Prioritization of Systems, related organic injury,emunctorial block and equalization are applied in both clinical cases.The ideptificttion of the lajter avoids homeopathic aggravations, essential for patients in severe states.
\end{abstract}

Conclusion: The theoretical bases for the understanding of clinical cases, in the Complex Systems Model of Carillo, with its 8 elements, namely: Structure (material body); Self-regulation (immaterial); Organization Pattern; Dissipation; Autopoiesis; Adaptation; Cognition and Consciousness, allow an expanded understanding of the health disease process.

Received: March 1, 2018. Accepted: April 26, 2018.

(C) International Journal of High Dilution Research.

Not for commercial purposes. 